\title{
Structure, thermal and fracture mechanical properties of benzoxazine-modified amine-cured DGEBA epoxy resins
}

\author{
S. Grishchuk ${ }^{1}$, Z. Mbhele ${ }^{2}$, S. Schmitt ${ }^{1}$, J. Karger-Kocsis ${ }^{2,3 *}$ \\ ${ }^{1}$ Institut für Verbundwerkstoffe GmbH (Institute for Composite Materials), Kaiserslautern University of Technology, \\ D-67663 Kaiserslautern, Germany \\ ${ }^{2}$ Polymer Technology, Faculty of Engineering and the Built Environment, Tshwane University of Technology, Pretoria \\ 0001, Republic of South Africa \\ ${ }^{3}$ Department of Polymer Engineering, Faculty of Mechanical Engineering, Budapest University of Technology and \\ Economics, H-1111 Budapest, Hungary
}

Received 18 November 2010; accepted in revised form 20 January 2011

\begin{abstract}
First, traditional diamine hardeners of epoxy resins (EP) were checked as potential accelerators for the benzoxazine (BOX) homopolymerization. It was established that the acceleration effect depends on both the type and amount of the diamine compounds. In the follow-up work amine-curable diglycidyl ether bisphenol A (DGEBA) type EP was modified with BOX keeping the EP/BOX ratio constant (75/25 wt.\%). The amine hardeners, added in the EP in stoichiometric amounts, were of aliphatic and aromatic nature, viz. diethylenetriamine (DETA), 4,4'-diaminodiphenyl methane (DDM), and their 1/1 mixture. The thermal, viscoelastic, flexural and fracture mechanical properties of the EP/BOX hybrids were determined and compared to those of the reference EPs. Based on dynamic-mechanical thermal analysis and atomic force microscopy the formation of co-network between EP and BOX was concluded. Homopolymerized BOX was built in the network in nanoscaled inclusions and it was associated with internal antiplasticization. Incorporation of BOX improved the charring, enhanced the flexural modulus and strength, and reduced the glass transition of the parent EP. The fracture toughness and energy were not improved by hybridization with BOX.
\end{abstract}

Keywords: thermosetting resins, benzoxazine, epoxy resin, fracture mechanics, morphology

\section{Introduction}

Polybenzoxazines represent a rather new class of thermosets formed by ring-opening polymerization (ROP) of the benzoxazine (BOX), usually 1,3-benzoxazine precursors. Nowadays they are considered as most promising matrix materials for composites in future aerospace applications. This expectation is based on their excellent thermal properties (high glass transition temperature, $T_{\mathrm{g}}$ ), low flammability (high char yield), high stiffness, low water uptake, and practically no shrinkage upon curing (e.g. [13]). As the curing of BOX occurs via ROP no volatile by-products appear which supports the pro- duction of void-free composites. A further benefit in linked with the easy synthesis of BOX, the monomers of which may be very versatile. Versatility is given by the fact that beside the necessary formaldehyde various phenol and amine compounds may be selected for the synthesis of BOX. On the other hand, the thermally-induced polymerization of BOX takes place at rather high temperature $\left(T>200^{\circ} \mathrm{C}\right)$ which is hardly acceptable by the praxis. A further problem, early recognized [4], is that the crosslink density of polybenzoxazine is surprisingly low considering its high stiffness and $T_{\mathrm{g}}$ when comparing with other thermosets of similar

\footnotetext{
${ }^{*}$ Corresponding author, e-mail: karger@pt.bme.hu
}

(c) BME-PT 
properties. This was explained by massive H-bonding occurring between the phenolic $-\mathrm{OH}$ and tertiary amines of the Mannich linkage formed via ROP in BOX ([1-3,5 and references therein $])$. Though the development of BOXs followed different directions in the past two decades [2-3, 5-6], the reduction of the temperature of polymerization (curing) and the increase of the crosslink density remained always top priority issues.

The ROP of BOX can be catalyzed by both basic and acidic compounds. In the open literature lots of different compounds have been checked in respect to their potential catalytic activity, whereby emphasis was put mostly on acidic compounds [1,7]. Markedly less works were devoted to the potential acceleration effect of basic compounds, and especially those of amine-group containing ones, on the BOX polymerization. The latter is, however, of paramount importance when the increase of the crosslink density of polybenzoxazines is targeted by coreactions (copolymerization, co-crosslinking) with epoxy resins (EPs). Recall that amines are the usual hardeners of low temperature curable EPs.

To increase the crosslink density of BOXs by cocrosslinking with EPs was always a favored research direction. In their pioneering work Ishida and Allen [4] prepared BOX/EP 'copolymers' by exploiting the reaction between the phenolic groups $(-\mathrm{OH})$ of the ring-opened BOX and epoxy (oxirane) groups of the EP. Accordingly, no external EP curing agent (hardener) has been used to prepare the EP/BOX hybrids. The corresponding hybrids showed enhanced $T_{\mathrm{g}}$, high crosslink density and ductility over the BOX homopolymers. The above reaction pathway, i.e. BOX as hardener for EP, was addressed by other researchers studying the related mechanisms [8-9] and the effects of the chemical build-up of the components [8]. Amine compounds may have an acceleration effect (thermal kick-off) on the BOX polymerization as demonstrated by Kimura et al. [10]. Recently, amine curable EP resins were also modified with BOX. Rao and Pathak [11] used phenalkamine as EP curing agent and concluded that the reactions between EP and BOX occur in two-steps. At low temperature the EP reacts with the amine, whereas at high temperature the ROP of BOX is immediately followed by cocrosslinking reactions occurring between the phe- nolic - $\mathrm{OH}(\mathrm{BOX})$ and epoxy groups (EP). A twostep reaction was proposed also for a special BOX end capped EP cured by aromatic diamine (diamino diphenyl sulphone) [12]. In a very recent paper Agag et al. [13] reported on the preparation of primary amine-functionalized BOXs and their curing. The differential scanning calorimetric (DSC) thermogram of the primary amine-functionalized BOX showed multiple exotherms above the melting and below the polymerization temperature of the corresponding BOX compound, which can only be assigned to reactions between the oxazine and primary amine $\left(-\mathrm{NH}_{2}\right)$ groups.

Considering the fact that primary diamines are the usual hardeners for low temperature curable EPs, it is straightforward to check their effects on the BOX polymerization. This has been done in the present work by selecting some amine hardeners with aliphatic, cycloaliphatic and aromatic backbones. A further aim of this work was to prepare BOX modified amine cured EPs and to study their structureproperty relationships.

\section{Experimental}

\subsection{Materials}

As potential accelerators for the BOX homopolymerization the following diamines have been selected: diethylenetriamine (DETA), 4,4'-diamino3,3'-dimethyl-dicyclohexylmethane (Aradur ${ }^{\circledR} 2954$ of Huntsman Advanced Materials, Basel, Switzerland), and 4,4'-diaminodiphenyl methane (DDM). DETA (melting and boiling temperatures -39 and $207^{\circ} \mathrm{C}$, respectively) and DDM (melting temperature: $92^{\circ} \mathrm{C}$ ) were procured from Sigma-Aldrich Chemie GmbH (Taufkirchen, Germany). Note that all of them are widely used EP hardeners. Moreover, due to their structure (aliphatic, cycloaliphatic and aromatic) the primary amines have different basic characters.

As bifunctional, diglycidyl ether bisphenol A based EP resin D.E.R. 331 (Dow Deutschland Anlagengesellschaft $\mathrm{mbH}$, Schwalbach, Germany) was selected. This EP has the following characteristics: epoxy equivalent weight: $182-192 \mathrm{~g} / \mathrm{eq}$. , viscosity and density at $T=25^{\circ} \mathrm{C} 11-14 \mathrm{~Pa} \cdot \mathrm{s}$ and $1.16 \mathrm{~g} / \mathrm{ml}$, respectively. The BOX used was an N-phenyl bisphenol A based 1,3-benzoxazine (Araldite MT $35600 \mathrm{CH}$ of Huntsman Advanced Materials). This 


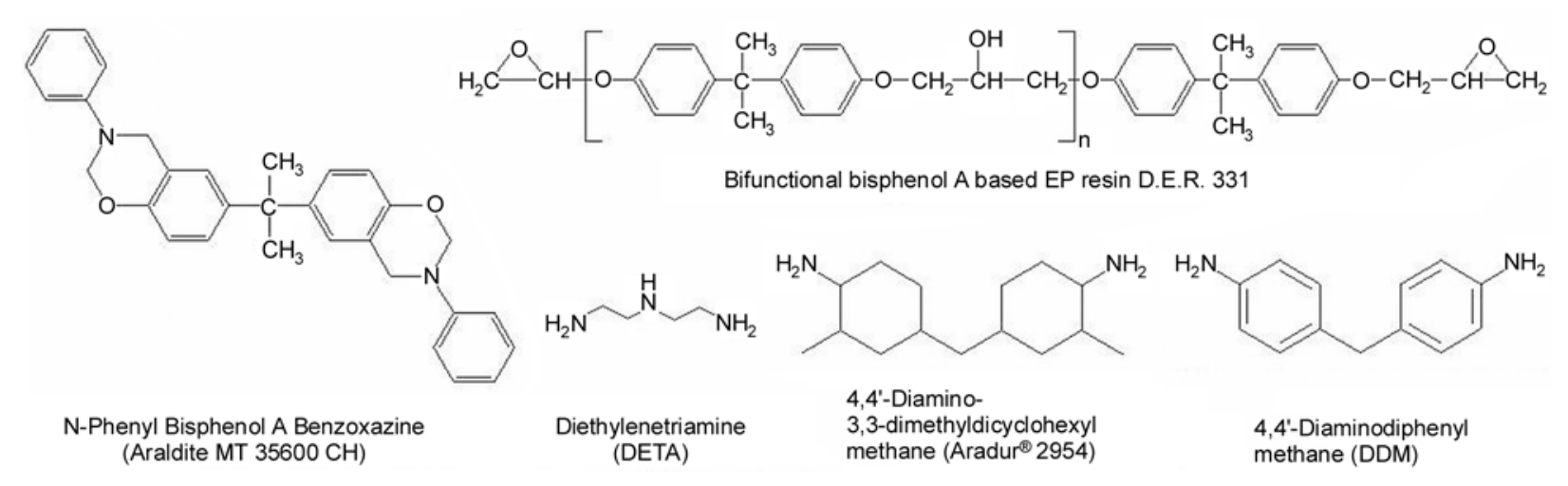

Figure 1. The chemical structures of the materials used

BOX with a density of $1.18 \mathrm{~g} / \mathrm{ml}$ at $R T$ has a melting range of $80-85^{\circ} \mathrm{C}$, and a viscosity range between 80 and $180 \mathrm{mPa} \cdot \mathrm{s}$ at $T=125^{\circ} \mathrm{C}$.

The chemical structures of the materials used are depicted in Figure 1.

\subsection{Sample/specimen preparation}

To check the potential acceleration effect of the amines they were added in 10 and $20 \mathrm{wt} \%$, respectively, to the powdered BOX followed by mixing in a mortar. The BOX/amine mixes were left for $24 \mathrm{~h}$ prior to their DSC testing. As demonstrated later by showing the related dynamic DSC scans the amine affected the homopolymerization of BOX differently. Based on the results two amines, viz. DETA and DDM along with their 1/1 mixture (molar ratio) were selected for the EP hardening. As the reactivities of DETA and DDM are very different both towards EP and BOX, our interest was to check their combination for which the DETA/DDM $=1 / 1$ has been selected. The EP/amine ratio was stoichiometric in all recipes. Though the BOX reacts with both the amine compounds (see later) and EP (as disclosed above), it was considered as an inert material. The EP(including hardener)/BOX ratio was fixed at $75 / 25 \mathrm{wt} . \%$.

The samples were prepared as described below. First, the EP was warmed to $70^{\circ} \mathrm{C}$ and kept for $30 \mathrm{~min}$ in order to melt the eventually crystalline fraction. Next, the powdered BOX was added to the warm EP and mixed thoroughly (1900 revolutions per minute, rpm) for $5 \mathrm{~min}$. The mix was placed in a thermostatic oven and stored at $T=110^{\circ} \mathrm{C}$ for $40 \mathrm{~min}$ to dissolve the BOX. Afterwards the amine was introduced by mixing (160 rpm) for $4 \mathrm{~min}$. Finally, the mixture was deareated in vacuo and poured in open molds manufactured from polytetra-

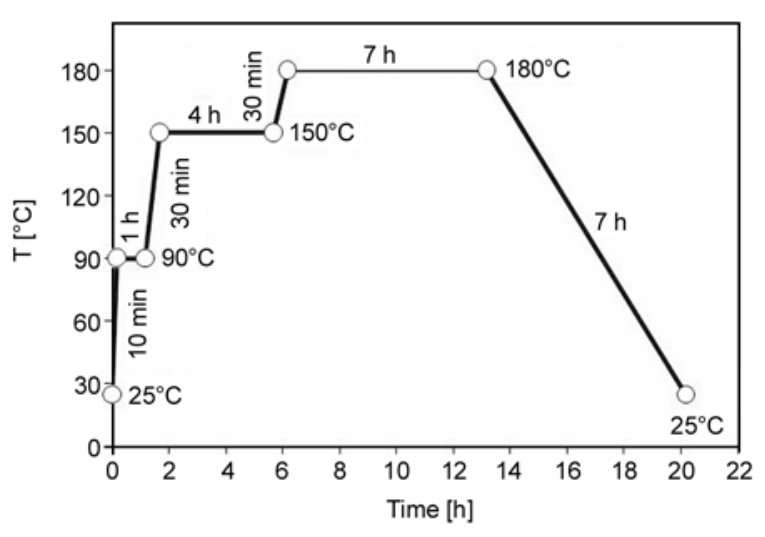

Figure 2. Cure cycle of the EP and EP/BOX hybrids

fluoro ethylene (PTFE). The PTFE molds contained the cavities of the rectangular bars and compact tension (CT) specimens used for testing (see later). The cure cycle (temperature vs. time) of the samples is depicted in Figure 2. Curing of the resins according to Figure 2 occurred in a programmable thermostatic oven of Kendro Laboratory Products (Langenselbold, Germany).

\section{Thermal and viscoelastic properties}

A DSC 821e (Mettler Toledo, Giessen, Germany) thermal analyzer was used to investigate the BOX homopolymerization in presence and absence of the various diamines listed before, and to detect the $T_{\mathrm{g}}$ of the EP/BOX hybrids prepared. DSC thermograms were registered in the temperature range from $T=0$ to $300^{\circ} \mathrm{C}$ at a heating rate of $10^{\circ} \mathrm{C} / \mathrm{min}$ under $\mathrm{N}_{2}$ flushing $(30 \mathrm{ml} / \mathrm{min})$. The sample weight varied between 10 and $20 \mathrm{mg}$.

Dynamic mechanical thermal analysis (DMTA) was taken on rectangular specimens $(60 \times 8 \times$ $4 \mathrm{~mm}^{3}$; length $\times$ width $\times$ thickness) in three point bending configuration (span length: $50 \mathrm{~mm}$ ) at $1 \mathrm{~Hz}$ using a DMA Q800 of TA Instruments (New Castle, DE, USA). Tests were performed at a constant 
amplitude $(50 \mu \mathrm{m})$ using sinusoidal oscillation and under dynamic conditions in the interval $T=$ $-100 \ldots 300^{\circ} \mathrm{C}$ at a heating rate of $1{ }^{\circ} \mathrm{C} / \mathrm{min}$.

The hybrid resins were subjected to thermogravimetric analysis (TGA) in a DTG-60 device of Shimadzu (Columbia, MD, USA). The TGA experiments were conducted under nitrogen atmosphere ( $30 \mathrm{ml} / \mathrm{min}$ ) in the temperature range $T=25 \ldots$ $600^{\circ} \mathrm{C}$ with heating rate $10^{\circ} \mathrm{C} / \mathrm{min}$.

\subsection{Flexural and fracture mechanical behavior}

The flexural properties, namely, modulus and strength of the hybrid resins, were determined on rectangular specimens $\left(60 \times 8 \times 4 \mathrm{~mm}^{3}\right.$; length $\times$ width $\times$ thickness) in three point bending at room temperature according to EN63. The span length of the specimens was $50 \mathrm{~mm}$ and their loading on a Zwick 1474 (Zwick GmbH, Ulm, Germany) universal testing machine occurred with deformation rate $v=1 \mathrm{~mm} / \mathrm{min}$.

The fracture toughness $\left(K_{\mathrm{c}}\right)$ and fracture energy $\left(G_{\mathrm{c}}\right)$ were measured according to ISO 13586-1 standard. The tests were done on the Zwick 1445 machine at room temperature $(R T)$ with a crosshead speed of $v=1 \mathrm{~mm} / \mathrm{min}$. The CT specimens (dimension: $35 \times 35 \times 3 \mathrm{~mm}^{3}$; length $\times$ width $\times$ thickness) were notched before loading by sawing. The sawn notch of the CT specimens was sharpened by a razor blade. The razor blade, fixed in a rig, was positioned in the notch root before hitting the fixing rig with a hammer. This 'taping' yielded the desired sharp crack.

\subsection{Morphology inspection}

To get an insight in the morphology of the hybrid systems the techniques scanning electron and atomic force microscopy (SEM and AFM, respectively) were adapted. The fracture surface of CT specimens has been investigated in SEM using a JSM 540 device of Jeol (Tokyo, Japan). The surface was coated with an $\mathrm{Au} / \mathrm{Pd}$ alloy prior to SEM inspection using a Balzers SCD 050 (Balzers, Lichtenstein) sputtering apparatus.

AFM scans were taken on polished samples by an AFM device (Veeco/Digital Instruments GmbH, Mannheim, Germany) in tapping mode, and the related height- and phase-contrast images captured. Commercial silicon cantilever (Pointprobe ${ }^{\circledR} \mathrm{NCH}$ of
Nanosensors, Neuchatel, Switzerland) with a nominal tip radius of less than $10 \mathrm{~nm}(120 \mu \mathrm{m}$ cantilever length, $4 \mu \mathrm{m}$ thickness, $30 \mu \mathrm{m}$ width and spring constant at $42 \mathrm{Nm}^{-1}$, Nanosensors, Neuchatel, Switzerland) was employed under its fundamental resonance frequency of about $330 \mathrm{kHz}$. The scan rates were set at $0.5 \mathrm{~Hz}$ for all images.

\section{Results and discussion}

\subsection{Effects of diamines on the BOX polymerization}

Figure 3 displays the DSC thermograms of BOX with and without the diamines selected.

It is clearly seen that all amines exhibited the supposed acceleration effect as the peak linked with the polymerization of $\mathrm{BOX}\left(T=253^{\circ} \mathrm{C}\right)$ was shifted toward lower temperatures. This is the right place to mention that we do not use the term 'catalytic effect' because the amount of amines is much too high for catalysts. In contrast to the aromatic diamine, in the traces of BOX with DETA and the cycloaliphatic diamine two exothermic peaks could be resolved. The high temperature peak should be assigned to the BOX homopolymerization. The low temperature peak, on the other hand, obviously reflects the reaction between $\mathrm{BOX}$ and amine. This finding is in line with that of Agag et al. [13]. On the other hand, neither the amine consumption nor the related reaction were studied in detail. It is noteworthy that the low temperature exotherm peaks at lower tempera-

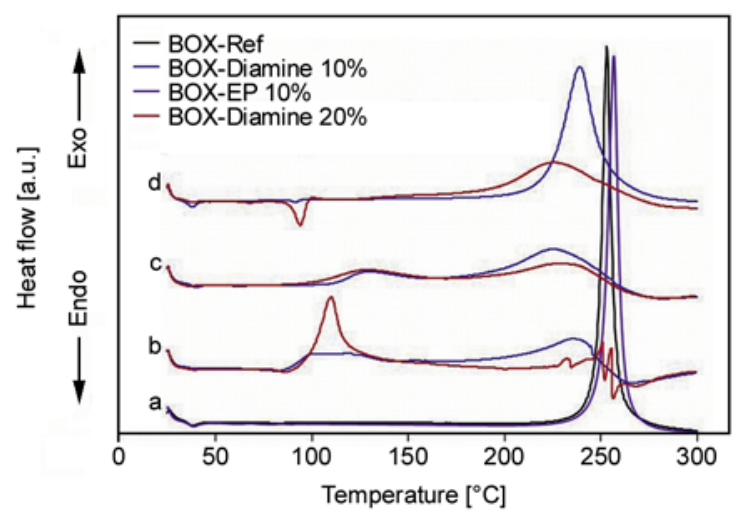

Figure 3. DSC traces showing the thermally-induced polymerization of BOX with and without $10 \mathrm{wt} . \% \mathrm{EP}$ (a), as well as the effects of aliphatic (b), cycloaliphatic (c) and aromatic diamines (d), added in 10 and $20 \mathrm{wt} . \%$, respectively. Notes: scatter in the DSC traces of BOX/DETA at $T>$ $220^{\circ} \mathrm{C}$ is due to the decomposition of DETA. BOX combined with EP (without amine hardener) does not affect much the curing 
ture for the DETA than for the cycloaliphatic diamine. This suggests differences in the basic character of the diamines which follows the ranking: aromatic $<$ cycloaliphatic $<$ aliphatic. It is also well resolved that with increasing amine content the intensity of the low temperature exotherm increases, whereas the high temperature one decreases. The thermal behavior of the BOX/DDM system differs markedly from BOX/DETA and BOX/cycloaliphatic diamine. In BOX/DDM only one exothermic peak appears. Accordingly, the BOX homopolymerization is superimposed to the oxazine/amine reaction. With increasing DDM content the exothermic peak is shifted toward lower temperatures whereby its intensity is highly reduced. Parallel to that the onset of this peak (i.e. where deviation starts from the base line) was markedly reduced. To sum up the above results one can establish that diamines are suitable accelerators of the BOX polymerization and the acceleration effect strongly depends on both their chemical structure and amount. The DSC traces in Figure 3 substantiate that the starting temperature for BOX curing (second exothermic peak) lies at $T \approx 180^{\circ} \mathrm{C}$. That was the reason to select this temperature along with a long holding time for the final step of the cure cycle given in Figure 2. The large difference in the acceleration of BOX polymerization between DETA and DDM prompted us to select them, and consider their 1/1 mixture, as well, as EP hardeners.

\subsection{Thermal and viscoelastic properties of EP/BOX hybrids}

Figure 4 shows the DSC traces of the amine-cured EP and EP/BOX hybrids. The $T_{\mathrm{g}}$ steps are well resolved for all systems. As expected, crosslinking

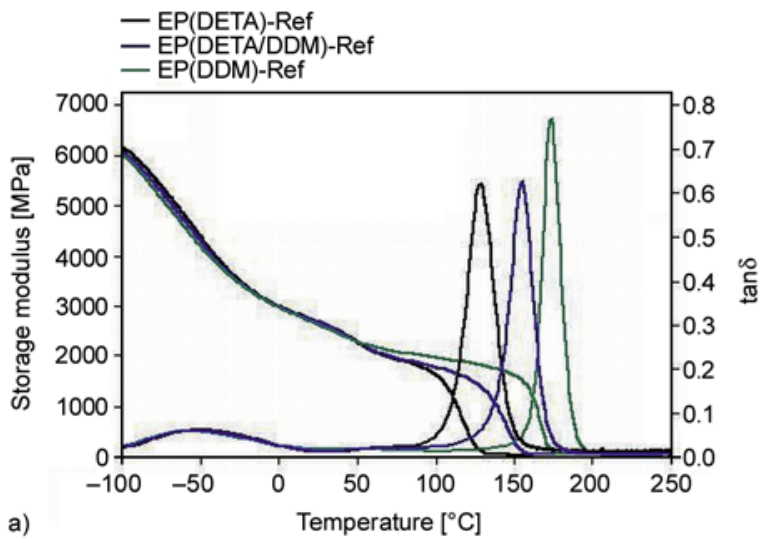

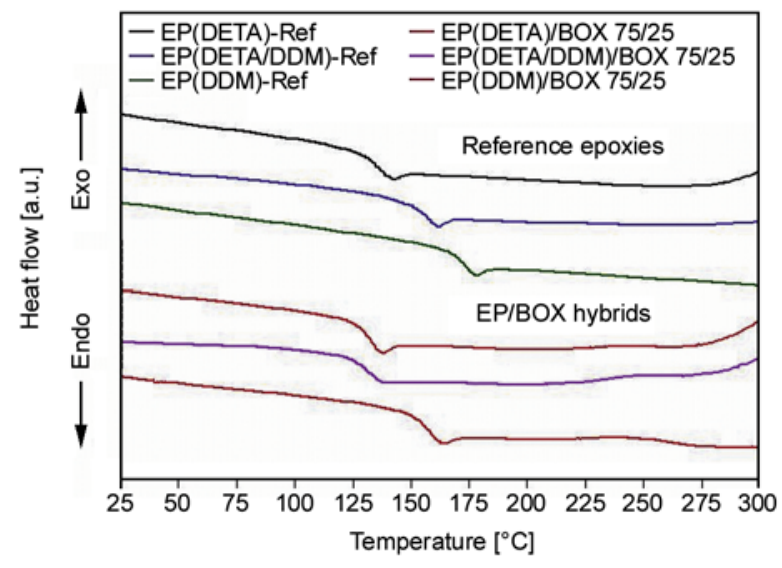

Figure 4. DSC thermograms for the amine-cured EP and $\mathrm{EP} / \mathrm{BOX}$ hybrids

with DDM yielded the highest, with DETA the lowest $T_{\mathrm{g}}$, and the $T_{\mathrm{g}}$ of the EP cured with mixed DETA/DDM (1/1) is in between. The EP/DETA starts to decompose at $T>270^{\circ} \mathrm{C}$ based on the exothermic flank in the corresponding curve. Effects of the diamines on the $T_{\mathrm{g}}$ of the EP/BOX $(75 / 25 \mathrm{wt} . \%)$ differ from those noticed for the EP reference samples. Though DDM gives the highest $T_{\mathrm{g}}$, the $T_{\mathrm{g}}$ data are similar for DETA- and DETA/ DDM-cured EP/BOX. The presence of BOX did not enhance the $T_{\mathrm{g}}$, just the opposite tendency happened. This suggests that the $\mathrm{EP} /$ diamine ratio was no more stoichiometric due to the reaction between the oxazine and primary amine groups. The shallow exothermic peak at $T \approx 240^{\circ} \mathrm{C}$ may hint that the BOX was not fully (co)cured in the related sample. The rise of the DSC trace in exothermic direction at $T>275^{\circ} \mathrm{C}$ reflects the onset of degradation.

Figure 5 compares the DMTA spectra of the aminecured EP and EP/BOX (75/25 wt.\%) hybrids.

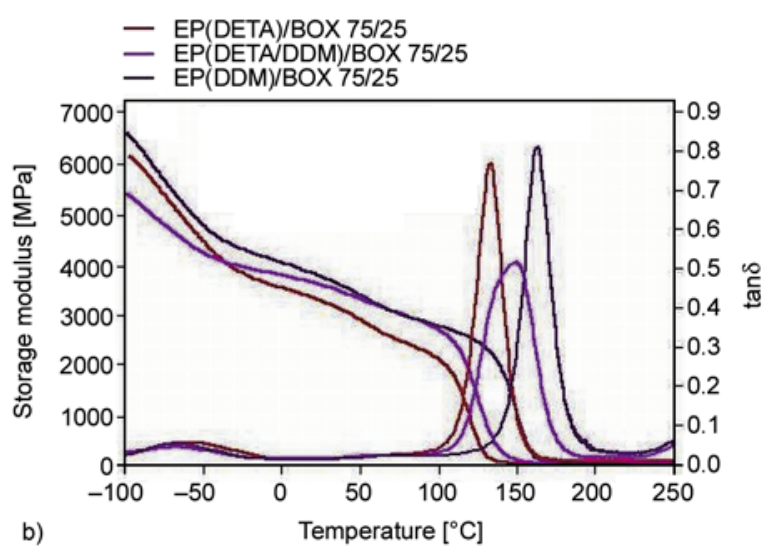

Figure 5. Storage modulus $\left(E^{\prime}\right)$ and mechanical loss factor $(\tan \delta)$ in function of temperature for the amine-cured EPs (a) and EP/BOX hybrids (b) 
The $E^{\prime}$ vs. $T$ traces of the amine-cured EPs split from each other only at $T>50^{\circ} \mathrm{C}$. As expected, the highest stiffness and $T_{\mathrm{g}}$ were delivered by DDM, followed by DMM/DETA and the lowest one presented the DETA-cured EP. Based on the $\tan \delta$ vs. $T$ traces the type of the amine did not influence the beta-relaxation $\left(T \approx-50^{\circ} \mathrm{C}\right)$ by contrast to the alpha-relaxation $\left(T_{\mathrm{g}}\right) . T_{\mathrm{g}}$ values, read at the peak temperature of the alpha-relaxation, followed the ranking: DETA $<$ DETA/DDM $<$ DDM in concert with the DSC results. The $T_{\mathrm{g}}$ values are summarized in Table 1.

The course of the $E^{\prime}$ vs. $T$ traces of EP/BOX is not as smooth as found for the reference EPs. On the other hand, comparing the corresponding $E^{\prime}$ vs. $T$ traces for EP and EP/BOX (75/25 wt.\%) in Figure $5 \mathrm{a}$ and $5 \mathrm{~b}$, respectively, one can recognize that modification with BOX improved the stiffness of the EP. Comparing the $\tan \delta$ vs. $T$ traces of the EP and EP/BOX (75/25 wt.\%) containing the same diamine, two striking features can be observed: i) $T_{\mathrm{g}}$ was reduced by the incorporation of $\mathrm{BOX}$ (which is in line with the DSC results (cf. Figure 4 and Table 1), and ii) the $\tan \delta$ peak of EP/BOX cured with the mixed amines (DETA/DDM) became broader than in the corresponding EP. Stiffness increase parallel with $T_{\mathrm{g}}$ decrease are usually caused by antiplasticizers, which is a known phenomenon also for EPs (e.g. [14-15]). The so-called internal antiplasticization caused by a change of the network structure. This is observed for non-stoichiometric or partially reacted epoxy-amine systems or when using a monoamine as a chain extender [14]. The two former features are present in our case due to the incorporation of $\mathrm{BOX}$ : $\mathrm{BOX}$ reacts namely with both amine and EP, but was considered as nonreactive additive in our formulations. It was also demonstrated that that antiplasticization affects the beta-relaxation similarly as the reduction of crosslink density, i.e. shifts the related peak toward lower temperature [15]. This can be observed also in our case - cf. beta peak at $T \approx-75^{\circ} \mathrm{C}$ in Figure $5 \mathrm{~b}$.

The co-curing of EP with BOX is well reflected by the data of the rubber plateau modulus $\left(E_{\mathrm{R}}^{\prime}\right) \cdot E_{\mathrm{R}}^{\prime}$ data were read at $T_{\mathrm{g}}+30^{\circ} \mathrm{C}$ for the $\mathrm{EP}$ and $\mathrm{EP} / \mathrm{BOX}$ hybrids studied and are also listed in Table 1 . The $E_{\mathrm{R}}^{\prime}$ data can be used to estimate the crosslink density according the theory of rubber elasticity (Equation (1)):

$\nu_{\mathrm{c}}=\frac{E^{\prime}{ }_{\mathrm{R}}}{3 R T}$

where $v_{\mathrm{c}}$ is the crosslink density, $R$ is the gas constant, and $T$ is the absolute temperature (i.e. at $\left.T_{\mathrm{g}}+30^{\circ} \mathrm{C}\right)$.

The crosslink densities are also included in Table 1. The broadening of the $\tan \delta$ peak for the EP/BOX $(75 / 25 \mathrm{wt} . \%)$ can be explained by the difference in the reactivity between the related amines and the oxazine. The amine/oxazine reaction affects later on the EP curing and EP/BOX co-curing, as well.

The DMTA analysis revealed that the modification with BOX enhanced the stiffness ( $E$-modulus), decreased the crosslink density and reduced the $T_{\mathrm{g}}$. The decreasing crosslink density of the hybrids can be traced to the low crosslinking density of the homopolymerized BOX. Ranking of the neat EPs in respect to the crosslink density (EP(DDM)-Ref $>$ EP(DETA/DDM)-Ref $>$ EP(DETA)-Ref) differs from that of the EP/BOX series $(\mathrm{EP}(\mathrm{DDM}) / \mathrm{BOX} \geq$ EP(DETA $) / B O X>$ EP(DETA/DDM $/$ BOX $)$. This is due to the formation of an EP/BOX co-network, which is influenced by chemical reactions among the EP, amine hardener and BOX. This affects the distribution of the possible intra- and intermolecular hydrogen bonds, as well. According to our opinion the structure development in $\mathrm{EP} / \mathrm{BOX}$ hybrids is mostly controlled by differences in the chemical structure and reactivity of the diamines (DETA, DDM).

Table 1. Thermal and viscoelastic parameters of the resins prepared

\begin{tabular}{|c|c|c|c|c|c|c|c|}
\hline \multirow{2}{*}{ System } & \multicolumn{2}{|c|}{$\mathbf{T}_{\mathrm{g}}\left[{ }^{\circ} \mathbf{C}\right]$} & \multicolumn{2}{|c|}{$\mathbf{E}^{\prime}[\mathbf{M P a}]$} & \multirow{2}{*}{$\begin{array}{c}v_{\mathrm{c}} \\
{\left[\mathrm{mol} / \mathrm{dm}^{3}\right]}\end{array}$} & \multirow{2}{*}{$\begin{array}{l}\mathbf{T}_{\mathbf{2}} \% \\
{\left[{ }^{\circ} \mathbf{C}\right]}\end{array}$} & \multirow{2}{*}{$\begin{array}{c}\text { Char yield } \\
\text { [wt.\%] }\end{array}$} \\
\hline & DSC & DMTA & RT & $\mathrm{T}_{\mathrm{g}}+30^{\circ} \mathrm{C}$ & & & \\
\hline EP(DETA)-Ref & 135 & 130 & 2690 & 33 & 3.06 & 327 & 9.0 \\
\hline EP(DETA/DDM)-Ref & 155 & 155 & 2690 & 41 & 3.59 & 338 & 14.0 \\
\hline EP(DDM)-Ref & 173 & 174 & 2630 & 43 & 3.61 & 362 & 17.5 \\
\hline EP(DETA)/BOX (75/25) & 132 & 134 & 3245 & 28 & 2.57 & 317 & 14.0 \\
\hline EP(DETA/DDM)/BOX (75/25) & 133 & 151 & 3560 & 23 & 2.03 & 309 & 25.0 \\
\hline EP(DDM)/BOX $(75 / 25)$ & 158 & 164 & 3720 & 30 & 2.58 & 335 & 22.3 \\
\hline
\end{tabular}




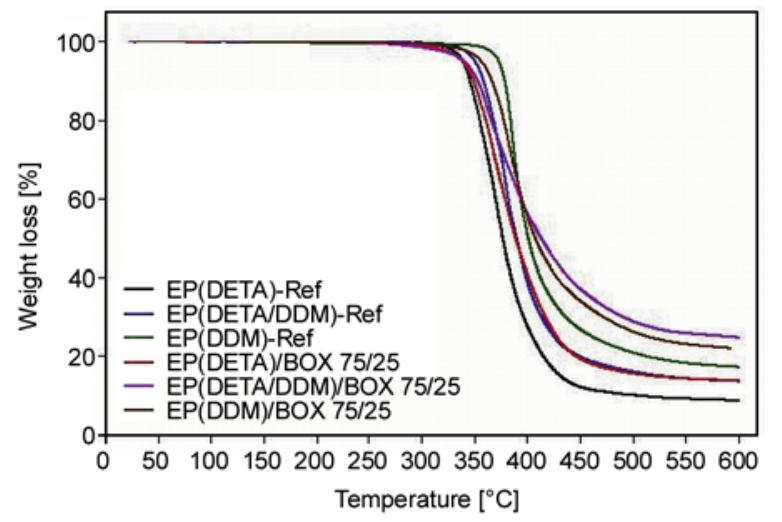

Figure 6. TGA traces registered for the EP and EP/BOX (75/25 wt.\%) hybrids

It remains, however, an open issue how the $\mathrm{BOX}$ units are incorporated into the EP network, and whether or not BOX is completely cured.

The TGA curves, registered on the EP and EP/BOX systems confirm that BOX incorporation improved the charring, in fact $-\mathrm{cf}$. Figure 6 . The temperature values linked with 2 wt. $\%$ loss and the char yield at $T=600^{\circ} \mathrm{C}$ are listed in Table 1, too. TGA traces in Figure 6 demonstrate that curing with DDM results in more temperature resistant EP-based systems than with DETA. A further finding is that the degra- dation onset was reduced by the BOX present, albeit the amount of the final residue (char) was enhanced. This suggests that the products of the reaction between oxazine and amine are less temperature resistant than those formed via epoxy/amine and epoxy/benzoxazine reactions.

\subsection{Static flexural and fracture mechanical properties}

The static flexural properties, i.e. $E$-modulus $\left(E_{\mathrm{f}}\right)$, strength $\left(\sigma_{\mathrm{f}}\right)$ and displacement at maximum load $\left(\varepsilon_{\mathrm{f}, \mathrm{m}}\right)$ are listed in Table 2 . One can establish that the $E$-modulus and flexural strength increased, whereas the displacement at maximum load decreased with BOX incorporation. Accordingly, BOX acted as reinforcement in the related EP/BOX hybrids. On the other hand, no clear tendency could be detected for the flexural properties in function of the type of the diamine compounds. The highest $E_{\mathrm{f}}$ and $\sigma_{\mathrm{f}}$ were found for the mixed amine-cured EP/BOX.

The fracture mechanical data, also listed in Table 2, yielded unexpected results. Modification with BOX slightly reduced both the fracture toughness $\left(K_{\mathrm{c}}\right)$ and fracture energy $\left(G_{\mathrm{c}}\right)$ compared to those of the reference resins. Moreover, the fracture mechanical

Table 2. Flexural and fracture mechanical data for the EP and EP/BOX hybrids (75/25 wt.\%).

\begin{tabular}{|c|c|c|c|c|c|}
\hline \multirow{3}{*}{ Material } & \multicolumn{5}{|c|}{ Properties } \\
\hline & \multicolumn{3}{|c|}{ Flexure } & \multicolumn{2}{|c|}{ Fracture mechanics } \\
\hline & $\mathbf{E}_{\mathrm{f}}[\mathrm{MPa}]$ & $\sigma_{\mathrm{f}}[\mathrm{MPa}]$ & $\varepsilon_{f, m}[\%]$ & $\mathrm{K}_{\mathrm{c}}\left[\mathrm{MPa} \cdot \mathrm{m}^{1 / 2}\right]$ & $\mathbf{G}_{\mathrm{c}}\left[\mathbf{J} \cdot \mathbf{m}^{2}\right]$ \\
\hline EP(DETA)-Ref & $2829 \pm 73$ & $111.0 \pm 9.6$ & $6.85 \pm 1.10$ & $0.78 \pm 0.03$ & $333 \pm 24$ \\
\hline EP(DETA/DDM)-Ref & $2644 \pm 119$ & $98.1 \pm 5.7$ & $8.02 \pm 2.48$ & $0.74 \pm 0.03$ & $308 \pm 39$ \\
\hline EP(DDM)-Ref & $2424 \pm 257$ & $121.8 \pm 9.2$ & $8.41 \pm 0.82$ & $0.80 \pm 0.07$ & $362 \pm 54$ \\
\hline EP(DETA)/BOX (75/25) & $3117 \pm 228$ & $116.7 \pm 25.8$ & $4.39 \pm 1.71$ & $0.68 \pm 0.07$ & $235 \pm 56$ \\
\hline EP(DETA/DDM)/BOX (75/25) & $3785 \pm 473$ & $167.4 \pm 26.5$ & $5.88 \pm 1.21$ & $0.74 \pm 0.10$ & $215 \pm 48$ \\
\hline $\mathrm{EP}(\mathrm{DDM}) / \mathrm{BOX}(75 / 25)$ & $3250 \pm 221$ & $147.6 \pm 15.2$ & $6.41 \pm 0.38$ & $0.64 \pm 0.08$ & $214 \pm 42$ \\
\hline
\end{tabular}

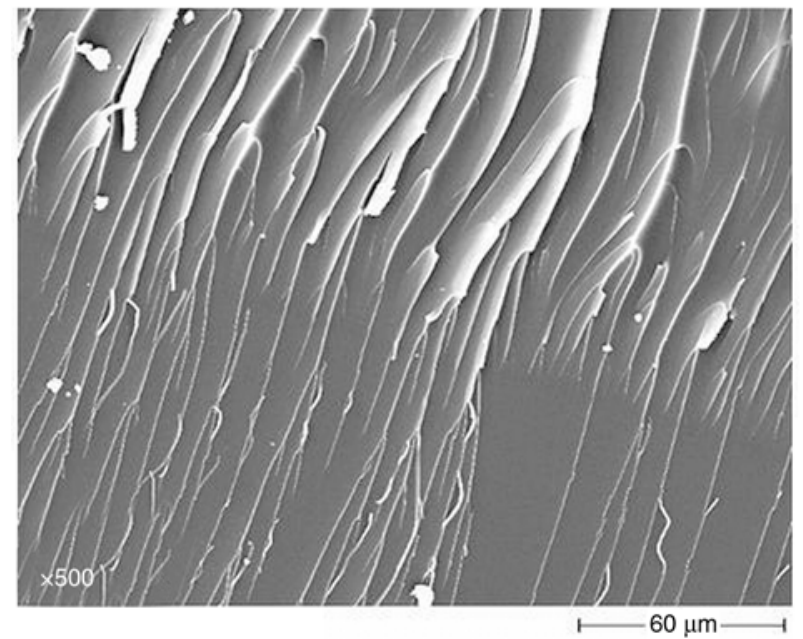

a)

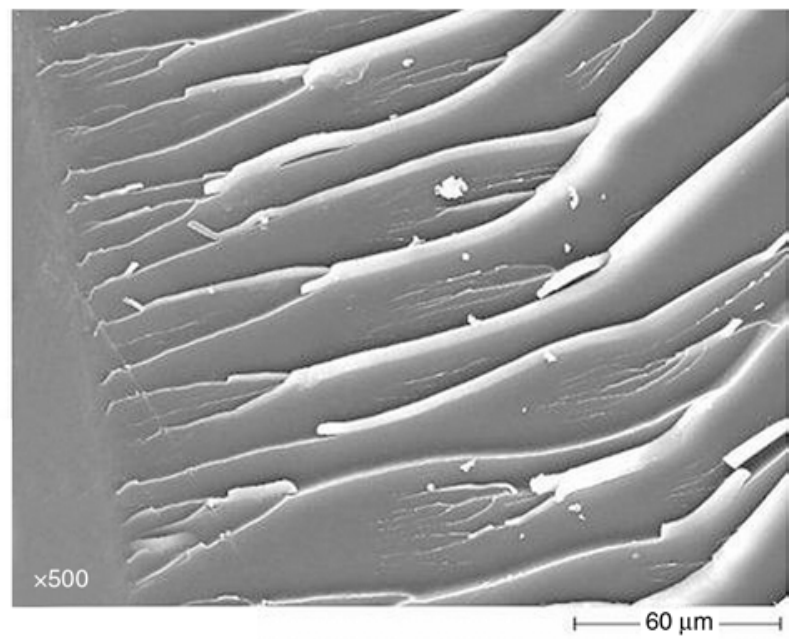

b)

Figure 7. SEM pictures taken of the fracture surface of EP(DETA/DDM) (a) and EP(DETA/DDM)/BOX (75/25 wt.\%) (b) 


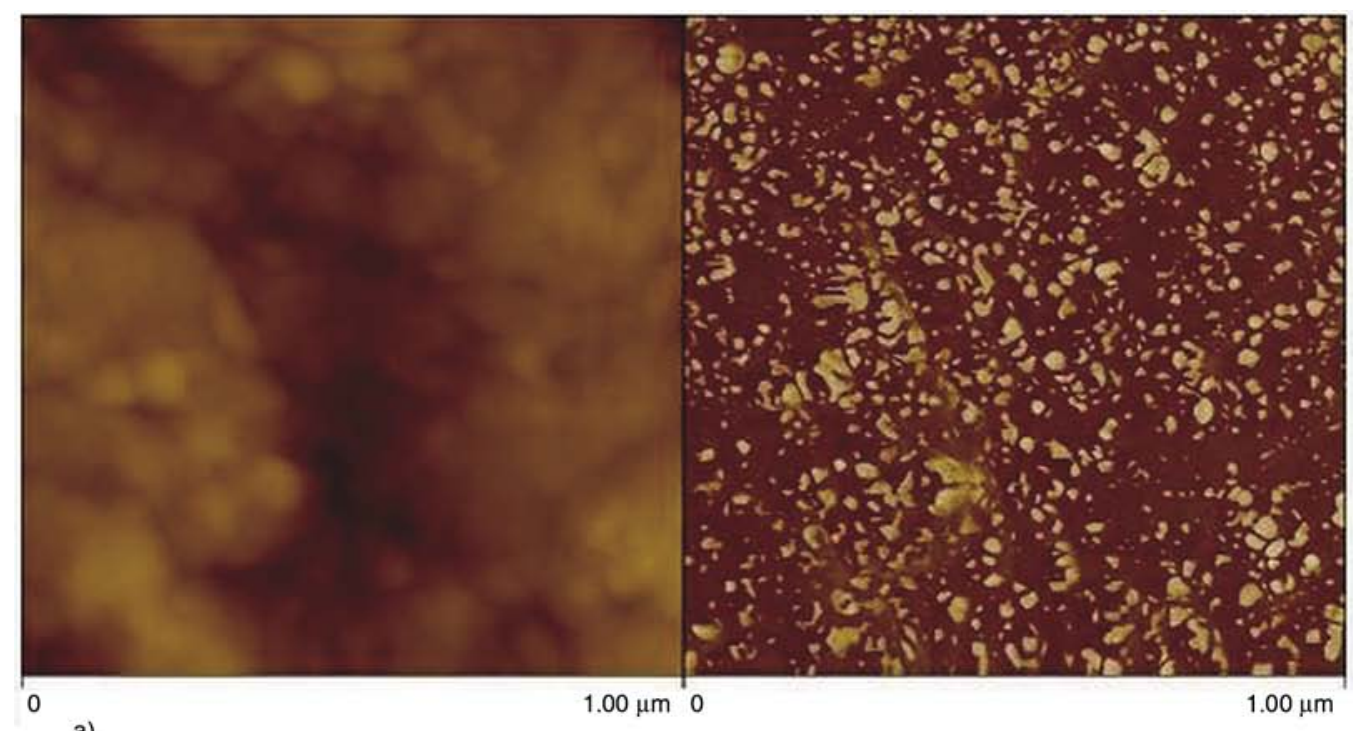

a)

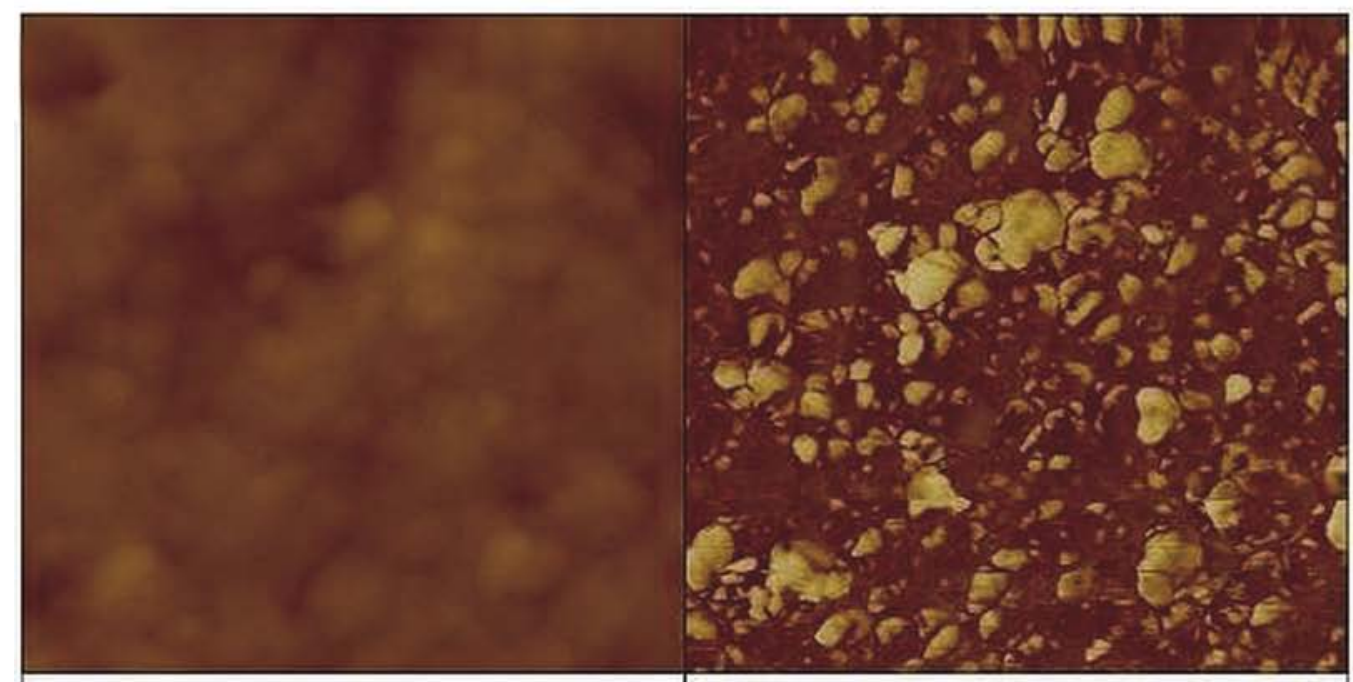

$1.00 \mu \mathrm{m} 0$

$1.00 \mu \mathrm{m}$

b)

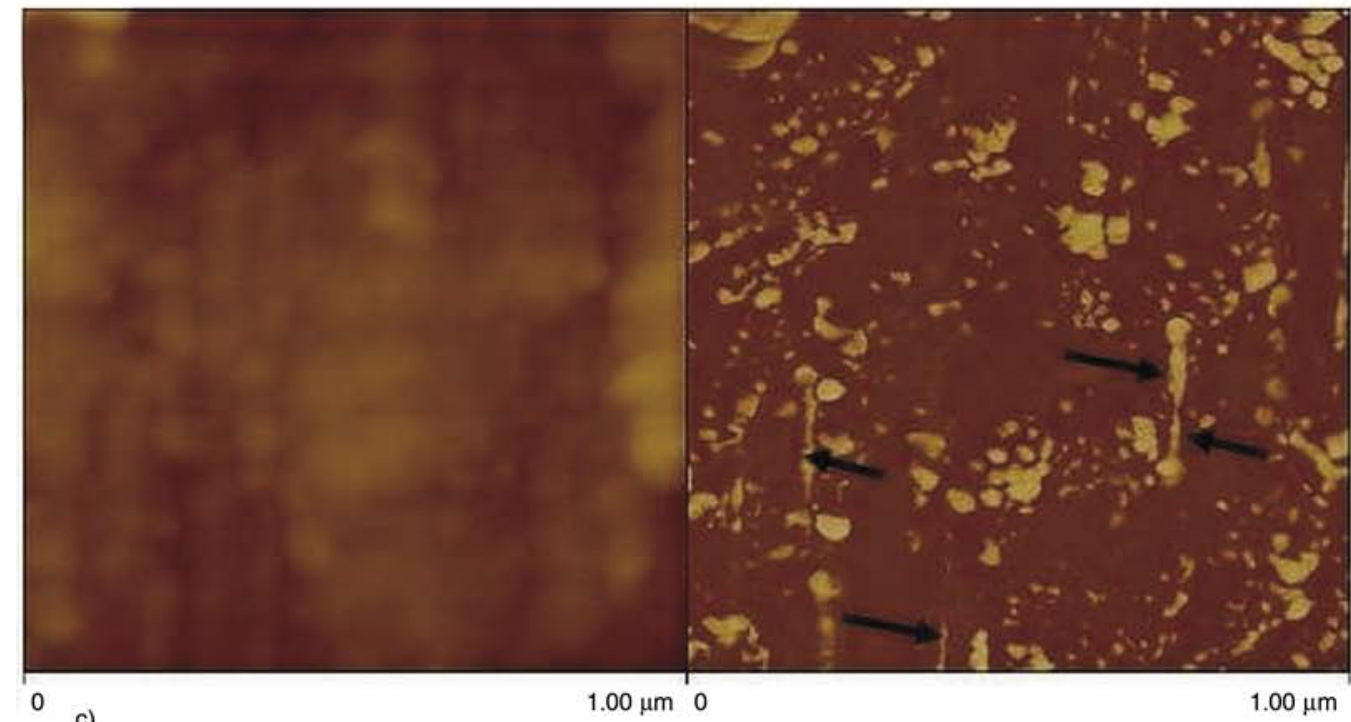

Figure 8. AFM height (left) and phase images (right) on the systems $\mathrm{EP}(\mathrm{DDM}) / \mathrm{BOX}=75 / 25 \mathrm{wt} . \%$ (a), $\mathrm{EP}(\mathrm{DETA}) / \mathrm{BOX}=$ $75 / 25$ wt.\% (b) and EP(DETA/DDM)/BOX $=75 / 25$ wt. $\%$ (c). Note: some vertically aligned 'tails' in the phase image picture $\mathrm{c}$ are related to experimentally-induced artefacts (indicated by arrows).- 
response of the systems was practically not influenced by the amine used. Based on the fact that the $E$-modulus and strength of the EP increased by BOX hybridization, one expected an increment in $K_{\mathrm{c}}$ and a reduction in $G_{\mathrm{c}}$ compared to the reference EP resins. This was not the case that should rely on the morphology of the hybrid resins. Nevertheless, the $K_{\mathrm{c}}$ and $G_{\mathrm{c}}$ data of the EP/BOX hybrids are superior to the polymerized neat $\mathrm{BOX}$.

\subsection{Morphology}

The fracture surfaces of the amine-cured EP and EP/BOX hybrids are very similar to each other. This, suggesting that the fracture mechanical parameters should be similar, as well (which is the case, in fact, as shown by the data in Table 2), is demonstrated on the example of EP(DETA/DDM) and EP(DETA/DDM)/BOX (75/25 wt.\%) in Figure 7. The appearance of the fracture surface suggests that BOX is well incorporated in the EP network, and its domain size (in case of eventual phase separation) should lie in submicron range. The AFM work supported this suggestion (see below).

The AFM height and phase images, taken from the polished surfaces of the EP/BOX system hardened by different amines are depicted in Figure 8 . The white spots in the AFM phase images represent the homopolymerized BOX. In case of DDM hardener, the thermally homopolymerized BOX is finely and uniformly dispersed in the EP matrix. The size of the polymerized BOX inclusions is in the range of 5-100 $\mathrm{nm}$ (main fraction is in the range of 7.5$45 \mathrm{~nm}$ ). By contrast, the dispersion of the homopolymerized BOX in the DETA-hardened EP is coarse and broad (particle size of $15-150 \mathrm{~nm}$ ). The change in the BOX dispersion is linked with the phase segregation between EP and BOX, governed by the gelling/crosslinking of EP. The latter is much faster and occurs at lower temperatures with DETA than with DDM hardener. This results in a fine distribution of homolymerized BOX in the EP matrix with DDM and a coarse one with DETA hardening. As, expected, the polymerized BOX appears in a bimodal-like distribution of 7-120 nm particles in the EP(DETA/DDM)/BOX system (cf. Figure 8c).

\section{Conclusions}

It was established that amine hardeners accelerated the homopolymerization of benzoxazine (BOX).
Based on this knowledge an amine-curable bifunctional epoxy resin was modified with BOX at a fix ratio $(\mathrm{EP} / \mathrm{BOX}=75 / 25 \mathrm{wt} . \%)$ and the basic thermal and mechanical properties of the corresponding hybrid determined. As amine hardeners an aliphatic, an aromatic diamine, and their 1/1 mixture were selected. The properties were collated with those measured on the reference EP. The outcome of this research work can be summarized as follows:

Network structure and morphology

- The amine-hardened EP formed a co-network with the BOX. This contained nanoscaled inclusions of the homopolymerized BOX. The dispersion characteristics of the hompolymerized BOX depended on the amine type. The finest dispersion was found for DDM, whereas a coarse one for DETA hardener. This was traced to the phase segregation process governed by the gelling and crosslinking of the EP with the given diamine.

Thermal properties

- The $T_{\mathrm{g}}$ of the hybrid was lower than the reference EP that was traced to off-stoichiometry caused by the amine/oxazine reaction. The observed internal antiplasticizing effect of BOX in EP/BOX hybrids was traced also to off-stoichiometry, affected by the reaction between BOX and EP, as well. Although the thermal degradation of the hybrid preceded that of the reference EP, incorporation of BOX was associated with a pronounced increase in the char yield.

Mechanical properties

- BOX incorporation enhanced the stiffness $(E-$ modulus) and strength based on DMA and flexural tests. This was explained by the nanoscaled homopolymerized BOX, well connected to the EP network. On the other hand, none of the fracture mechanical parameters could be improved by adding BOX.

\section{Acknowledgements}

This work was done in the framework of a collaboration project between Germany and South Africa, sponsored by BMBF and NRF, respectively. It was also supported by the Advanced Manufacturing Technology Strategy program of DST (South Africa) and Hungarian Scientific Research Fund OTKA. The authors thank to Dr. P. Tsotra (Huntsman Advanced Materials, Basel, Switzerland) for the BOX delivery. 


\section{References}

[1] Reghunadhan Nair C. P.: Advances in addition-cure phenolic resins. Progress in Polymer Science, 29, 401498 (2004).

DOI: 10.1016/j.progpolymsci.2004.01.004

[2] Yagci Y., Kiskan B., Ghosh N. N.: Recent advancement on polybenzoxazine - A newly developed high performance thermoset. Journal of Polymer Science Part A: Polymer Chemistry, 47, 5565-5576 (2009). DOI: $10.1002 /$ pola.23597

[3] Santhosh Kumar K. S., Reghunadhan Nair C. P.: Rapra, Shawbury (2010).

[4] Ishida H., Allen D. J.: Mechanical characterization of copolymers based on benzoxazine and epoxy. Polymer, 37, 4487-4495 (1996).

DOI: 10.1016/0032-3861(96)00303-5

[5] Endo T., Sudo A.: Development and application of novel ring-opening polymerizations to functional networked polymers. Journal of Polymer Science Part A: Polymer Chemistry, 47, 4847-4858 (2009).

DOI: $10.1002 /$ pola. 23531

[6] Takeichi T., Agag T.: High performance polybenzoxazines as novel thermosets. High Performance Polymers, 18, 777-797 (2006).

DOI: $10.1177 / 0954008306068254$

[7] Ishida H., Rodriguez Y.: Catalyzing the curing reaction of a new benzoxazine-based phenolic resin. Journal of Applied Polymer Science, 58, 1751-1760 (1995). DOI: 10.1002/app.1995.070581013

[8] Rao B. S., Reddy K. R., Pathak S. K., Pasala A. R.: Benzoxazine-epoxy copolymers: Effect of molecular weight and crosslinking on thermal and viscoelastic properties. Polymer International, 54, 1371-1376 (2005).

DOI: $10.1002 /$ pi.1853
[9] Kimura H., Matsumoto A., Hasegawa K., Ohtsuka K., Fukuda A.: Epoxy resin cured by bisphenol A based benzoxazine. Journal of Applied Polymer Science, 68, 1903-1910 (1998).

DOI: $10.1002 /(\mathrm{SICI}) 1097-4628(19980620) 68: 12<1903$

$$
\because \text { AID-APP2>3.0.CO;2-P }
$$

[10] Kimura H., Matsumoto A., Ohtsuka K.: New type of phenolic resin: Curing reaction of phenol-novolac based benzoxazine with bisoxazoline or epoxy resin using latent curing agent and the properties of the cured resin. Journal of Applied Polymer Science, 112, 17621770 (2009).

DOI: $10.1002 /$ app. 29301

[11] Rao B. S., Pathak S. K.: Thermal and viscoelastic properties of sequentially polymerized networks composed of benzoxazine, epoxy, and phenalkamine curing agents. Journal of Applied Polymer Science, 100, 3956-3965 (2006).

DOI: $10.1002 / a p p .23008$

[12] Lin H. T., Lin C. H., Hu Y. M., Su W. C.: An approach to develop high- $T_{\mathrm{g}}$ epoxy resins for halogen-free copper clad laminates. Polymer, 50, 5685-5692 (2009). DOI: $10.1016 /$ j.polymer.2009.09.075

[13] Agag T., Arza C. R., Maurer F. H. J., Ishida H.: Primary amine-functionalized benzoxazine monomers and their use for amide-containing monomeric benzoxazines. Macromolecules, 43, 2748-2758 (2010). DOI: $10.1021 / \mathrm{ma} 902556 \mathrm{k}$

[14] Pascault J-P., Sautereau H., Verdu J., Williams R. J. J.: Thermosetting polymers. Marcel Dekker, New York (2002).

[15] Bershtein V. A., Peschanskaya N. N., Halary J. L., Monnerie L.: The sub- $T_{\mathrm{g}}$ relaxations in pure and antiplasticized model epoxy networks as studied by high resolution creep rate spectroscopy. Polymer, 40, 6687-6698 (1999). DOI: $10.1016 / \mathrm{S} 0032-3861(98) 00873-8$ 